University of Nebraska - Lincoln

DigitalCommons@University of Nebraska - Lincoln

The distribution of chlorpyrifos following a crack and crevice type application in the US EPA Indoor Air Quality Research House

D. M. Stout II

U.S. EPA, stout.dan@epa.gov

M. A. Mason

U.S. EPA

Follow this and additional works at: https://digitalcommons.unl.edu/usepapapers

Stout, D. M. II and Mason, M. A., "The distribution of chlorpyrifos following a crack and crevice type application in the US EPA Indoor Air Quality Research House" (2003). U.S. Environmental Protection Agency Papers. 179.

https://digitalcommons.unl.edu/usepapapers/179

This Article is brought to you for free and open access by the U.S. Environmental Protection Agency at DigitalCommons@University of Nebraska - Lincoln. It has been accepted for inclusion in U.S. Environmental Protection Agency Papers by an authorized administrator of DigitalCommons@University of Nebraska - Lincoln. 


\title{
The distribution of chlorpyrifos following a crack and crevice type application in the US EPA Indoor Air Quality Research House
}

\author{
D.M. Stout $\mathrm{II}^{\mathrm{a}, *}$ M.A. Mason ${ }^{\mathrm{b}}$ \\ ${ }^{a}$ US EPA National Exposure Research Laboratory, Exposure Measurement Analysis Branch, Research Triangle Park, NC 27711, USA \\ ${ }^{\mathrm{b}}$ US EPA National Risk Management Research Laboratory, Indoor Environment Management Branch, Research Triangle Park, \\ NC 27711, USA
}

Received 28 March 2003; received in revised form 28 July 2003; accepted 4 September 2003

\begin{abstract}
A study was conducted in the US EPA Indoor Air Quality (IAQ) Research House to determine the spatial and temporal distribution of chlorpyrifos following a professional crack and crevice application in the kitchen. Following the application, measurements were made in the kitchen, den and master bedroom over 21 days. Airborne concentrations were collected using both polyurethane foam (PUF) and the OSHA versatile sampler composed of XAD and PUF media located in tandem. Measured airborne concentrations were similar for the two samplers and were higher in the three rooms following the application. The highest measured concentrations were reached during the initial 24-h following application; concentrations subsequently declined over the 21-day study period to levels slightly above background. Spatial and temporal distributions onto surfaces were measured using $10-\mathrm{cm}^{2}$ rayon deposition coupons located on the floor. Sections were cut from existing carpet to determine the total extractable residues. Chlorpyrifos was measured from all matrixes in the kitchen, den and bedroom and the data shows the transport of airborne residues from the point of application to remote locations in the house. The findings are compared and discussed relative to another study conducted in which total release aerosols containing chlorpyrifos were activated in the IAQ research house and the resulting distributions evaluated. For both studies dose estimates were constructed for the exposure pathways using the Stochastic Human Exposure and Dose Estimation Model for pesticides.

The United States Environmental Protection Agency has been mandated to examine children's exposure to environmental pollutants such as pesticides. This research specifically reduces uncertainties associated with estimating children's potential exposures to residentially applied pesticides and provides inputs to further evaluate and validate residential exposure models which might be used to reduce exposures and perform risk assessments.
\end{abstract}

Published by Elsevier Ltd.

Keywords: Chlorpyrifos; Translocation; Pesticide; Residential exposure; Crack and crevice application

\section{Introduction}

Pesticides are applied in and around human habitations to control a variety of pests and may place toxicants in close proximity to humans. It has been demonstrated that pesticide residues may translocate

\footnotetext{
*Corresponding author. Tel./fax: + 1-919-541-5767.

E-mail address: stout.dan@epa.gov (D.M. Stout II).
}

from their original points of application as vapors, bound to particles, or through physical transport processes (Leidy et al., 1993; Lewis et al., 2001; Nishioka et al., 1997; Stout and Leidy, 2000). The principal factors that influence their movement are the compounds physiochemical properties, the substrates contacted, and the physical activities of humans and companion animals. Degrading factors such as photolysis and microbial activity influence pesticide residues 
less indoors than outdoors; as a consequence, pesticides may have increased persistence or accumulation in the indoor environment. Exposure to indoor pollutants such as pesticides may pose risks to occupants through inhalation, dermal absorption, and direct or indirect ingestion. Occupants may be more exposed immediately following the pesticide application where deposits are fresh, surface concentrations are maximal and volatilization from the source is highest. Crack and crevice type applications place the active ingredient of the pesticide formulation into voids where domestic pest species, such as the German cockroach (Blattella germanica), find refuge. Theoretically the crack and crevice application, as opposed to the activation of total release aerosols (TRA) or broadcast spray applications, reduces potential human exposures by placing the toxicant into discrete locations away from potential human contact.

A pilot experiment was conducted in the US EPA's Indoor Air Quality (IAQ) Research House to investigate the contribution of a crack and crevice application of the insecticide chlorpyrifos to airborne residue levels in the home and deposition onto target and non-target substrates. This experiment provides increased spatial resolution of surface concentrations and the distribution of chlorpyrifos within two rooms immediately following a crack and crevice type application. Discussion of the findings includes the distribution of residues from the point of application to spatially distant locations within the test house, and an evaluation of the potential for exposures following a residential treatment. In addition, comparisons are made with a previous experiment conducted in the EPA's IAQ Research House, which utilized a TRA application and a chlorpyrifos formulation (Mason et al., 2000). Chlorpyrifos is no longer registered for indoor, residential crack and crevice applications. However, these data contribute to understanding the relationships between indoor applications of semi-volatile pesticides and the movement of such compounds in the indoor environment and the potential for human exposure.

\section{Methods}

\subsection{The Research House}

The study reported here was conducted in November 2000, in the US EPA's IAQ Research House. The test house is an unoccupied one-story, nine-room (three bedroom, two bathrooms, den, living room, kitchen and dining room), ranch-style house located in a residential neighborhood in Cary, NC (Fig. 1). The interior volume of the test house contains a total $293 \mathrm{~m}^{3}$ with $122 \mathrm{~m}^{2}$ of living area. All rooms are void of furniture and covered with wall-to-wall pile or shag (den) nylon carpet except the kitchen and the bathrooms. The test house is characterized in that air exchange rates (indoor to outdoor), temperature, and relative humidity are continuously monitored. The rooms are open to the entry hallway and the kitchen (Fig. 1) and their physical separation is only partial. The kitchen is open to the den via a "pass-through opening".

\subsection{The pesticide application}

A $0.5 \%$ solution of chlorpyrifos (O,O-diethyl-O(3,5,6-trichloro-2-pyridinyl) phosphorothioate) was prepared as per label directions by diluting $78 \mathrm{ml}$ of a commercially available, emulsifiable concentrate formulation with $3700 \mathrm{ml}$ of tap water in a pre-cleaned 1-gal compressed air sprayer. The mixing of the concentrate and water was performed outside of the test house in order to minimize the potential for contamination of the house during this process. A total of $259 \mathrm{ml}$ of the finished solution was applied in the kitchen only (Fig. 1) theoretically providing $1.29 \mathrm{~g}$ of active ingredient applied. The application was performed by a licensed pest control operator using a compressed air sprayer operated at $<30 \mathrm{psi}$ and equipped with pin-stream-type spray tip. The application simulated a "clean-out" type treatment that is conventional for the control of a cockroach infestation and required about $15 \mathrm{~min}$ to complete. Here the dilute solution is systematically placed into the potential cockroach harborages such as the cracks and crevices of the cabinetry, and around and behind the stove, refrigerator and dishwasher. Prior to the application, all windows were closed and the furnace fan was turned off. Afterwards, the house thermostat was set to $22^{\circ} \mathrm{C}\left(72^{\circ} \mathrm{F}\right)$ for the duration of the experiment and the furnace fan was returned to the "on" position. The interior doors remained open throughout the test.

\subsection{Air monitoring}

Air monitoring was conducted using both commercially available polyurethane foam (PUF) tubes and the OSHA versatile sampler or OVS tubes (SKC Inc., Eighty-Four, PA). The PUF tube was a 76 by 20-mm PUF plug in glass filter housing. The PUF system was open faced with no particle cutoff inlet. The OVS tube consisted of a 74 by $13-\mathrm{mm}$ glass housing containing a quartz filter and two 140 and $270 \mathrm{mg}$ beds of XAD-2 sandwiched between PUF partitions. Both monitors were suspended $100-\mathrm{cm}$ above the floor in the living room, den and the master bedroom (Fig. 1). The sorbents were connected by Tygon tubing to SKC Universal XR sample pumps, which were calibrated to a flow rate of 3.8 and $1.01 / \mathrm{min}$ for PUF and OVS, respectively. Air was drawn over the media for a period of 24-h. The sample inlets were directed 


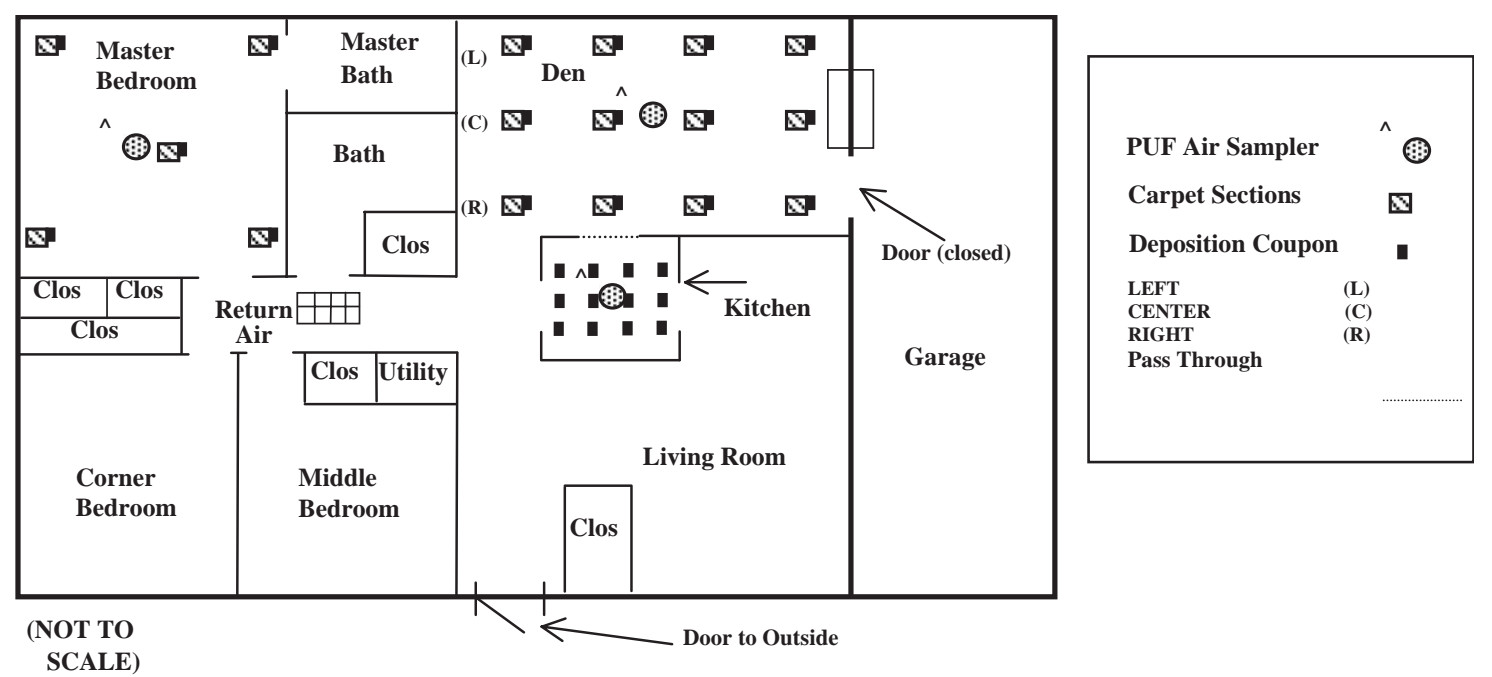

Fig. 1. An overview of the IAQ Research House with the sampling locations shown for the kitchen, den and master bedroom.

towards the floor. Samples were collected prior to the application and at days 1, 3, 7, 14 and 21 days post-application. Following sample collection, the PUF and OVS tubes were capped with aluminum foil and individually sealed in plastic bags. The tubes were put in ice chests at reduced temperatures for transport.

\subsection{Deposition coupons}

Johnson and Johnson Sof-Wick surgical sponges $\left(100 \mathrm{~cm}^{2}\right)$ were used to collect surface depositions of airborne chlorpyrifos following the application. Each deposition coupon consisted of a single rayon-based surgical sponge backed by solvent rinsed aluminum foil. The deposition coupons were placed on the floor in the kitchen, den, and bedroom (Fig. 1) and collected prior to, immediately following the application (the sample collection process was initiated after the application and required about $1 \mathrm{~h}$ to complete), and at days $3,7,14$ and 21 days post-application. At each sampling interval, each deposition coupon was replaced with a new coupon. Coupons were individually collected immediately following the application in the kitchen and den, but were aggregated in the bedroom. At all other sampling intervals, the deposition coupons in the kitchen and den were combined as a single sample by rows across the length of the room, except in the bedroom where all five coupons were combined. The samples were collected using clean, solvent-rinsed forceps, placed in labeled glass jars equipped with Teflon lined lids, and stored in ice chests at reduced temperatures for transport.

\subsection{Carpet sections}

Carpet sections were collected to determine if concentrations of chlorpyrifos measured from the carpeting (including the backing) increased. Prior to the insecticide treatment, 12 and 5 groups were cut from the den and bedroom carpeting, respectively, at locations adjacent to the deposition coupons. Each group consisted of six, $16 \mathrm{~cm}^{2}$ carpet sections (Fig. 1). The groups of carpet sections remained in place from the initiation of the study until they were collected at the respective sampling interval. The carpet sections were collected prior to, immediately following the application, and at days 3, 7, 14 and 21 days post-application. Samples in the den were combined across rows, while in the bedroom all five samples were aggregated at each interval. The samples were collected using solvent-rinsed forceps, placed in labeled glass jars, and stored in ice chests at reduced temperatures for transport.

\subsection{Chemical analysis}

Soxhlet extraction techniques were used to extract the PUF air monitors and carpet sections in a solvent of 5\% diethyl ether in hexane. The OVS and deposition coupons were extracted on a shaker table operated at $2500 \mathrm{rpm}$ for $1 \mathrm{~h}$ in a solvent of $5 \%$ diethyl ether in hexane. Samples were analyzed using a Hewlett-Packard 5890 gas chromatograph (GC) equipped with a liquid auto-sampler and electron capture detector. A DB-5 fused silica column $\left(30 \times 0.25 \mathrm{~mm}^{2}\right)$ was used to separate chlorpyrifos. The carrier flow rate was $2.0 \mathrm{ml} / \mathrm{min}$. The temperature program was initiated at $125^{\circ} \mathrm{C}$ and programmed to $200^{\circ} \mathrm{C}$ at $4^{\circ} \mathrm{C} / \mathrm{min}$ to $290^{\circ} \mathrm{C}$ at $8^{\circ} \mathrm{C} /$ min. The capillary injector was operated in the splitless 
mode for 1-min. Injector and detector temperatures were $240^{\circ} \mathrm{C}$ and $300^{\circ} \mathrm{C}$, respectively. Instrument calibration was performed using calibration standards containing chlorpyrifos, decachlorobiphenyl (surrogate) and 2,4,5tribromobiphenyl (internal). A five-point calibration curve using a quadratic fit was generated across an operating range of $10-250 \mathrm{pg} / \mu \mathrm{l}$.

A subset of samples for each matrix was selected to confirm the presence chlorpyrifos. The analysis was performed using Hewlett-Packard 6890N GC equipped with a liquid auto-sampler and mass spectrometer (MS). A Restek RTX-5 MS fused silica column ( $30 \mathrm{~m} \times 25 \mathrm{~mm}, 0.25 \mu \mathrm{m}$ film thickness) was used to resolve chlorpyrifos. The temperature program was as follows: initial temperature at $70^{\circ} \mathrm{C}$, hold for $2 \mathrm{~min}$; program to $225^{\circ} \mathrm{C}$ at $15^{\circ} \mathrm{C} / \mathrm{min}$; program to $260^{\circ} \mathrm{C}$ at $2^{\circ} \mathrm{C} / \mathrm{min}$; program to $300^{\circ} \mathrm{C}$ at $15^{\circ} \mathrm{C} / \mathrm{min}$, hold for $5 \mathrm{~min}$. The capillary injector was operated in the splitless mode for 1-min. The injector, thermal auxiliary line, quad and source were operated at temperatures of $280^{\circ} \mathrm{C}, 280^{\circ} \mathrm{C}, 150^{\circ} \mathrm{C}$ and $300^{\circ} \mathrm{C}$, respectively. The detector was operated in selected ion mode to monitor for the following masses: 244, 258, 286, 314, and 316.

\subsection{Other research house measurements}

The air exchange rates were determined by using the tracer gas decay technique (ASHRAE, 1985) and for the test period averaged $0.39 \pm 0.04$ air exchanges per hour for the entire house. Temperatures were measured in all rooms and outdoors and the relative humidity was measured in selected rooms and outdoors but are not reported here.

\subsection{Quality control}

Laboratory quality control included matrix blanks, spikes and duplicates of PUF, OVS, and deposition coupons and carpet sections. Field quality control was similar, but did not include carpet spikes. Chlorpyrifos was not detected from any of the laboratory or field blank samples. Fortified spikes containing $100 \mathrm{ng}$ of chlorpyrifos provided recovery efficiencies (mean \pm SEM) for field control samples of PUF, OVS, and deposition coupons of $114 \pm 6 \%, 103 \pm 6 \%$, and $98 \pm 5 \%$, respectively. Laboratory control samples of PUF, OVS, deposition coupons and carpet sections fortified at a similar level provided recovery efficiencies of $122 \pm 5 \%, 115 \pm 4 \%, 104 \pm 4 \%$ and $120 \pm 3 \%$, respectively. All recoveries were within the data quality objectives of $\pm 30 \%$ for quality control samples, which accounts for accepted levels of error typically associated with laboratory processes. A separate analysis was performed on a subset of samples using GC/MS and library results, comparisons of ions and retention times to confirm the presence of chlorpyrifos in all matrices.

\section{Results and discussion}

\subsection{Airborne concentrations}

Airborne concentrations of chlorpyrifos measured using PUF and OVS samplers, including field duplicates, agreed (Table 1). Pre-application measurements showed low levels of chlorpyrifos. The highest post application concentrations of chlorpyrifos were observed at the day 1 sampling intervals, declining by more than $70 \%$ by

Table 1

Airborne chlorpyrifos residues collected on PUF and OVS samplers following a crack and crevice type application in the IAQ research house

\begin{tabular}{|c|c|c|c|c|c|c|c|c|c|}
\hline \multirow[t]{2}{*}{ Sample type } & \multirow[t]{2}{*}{ Room } & \multicolumn{8}{|c|}{ Day/concentration $\left(\mu \mathrm{g} / \mathrm{m}^{3}\right)$} \\
\hline & & Pre & $3 \mathrm{~h}$ & $1^{\mathrm{a}}$ & 2 & 3 & 7 & 14 & 21 \\
\hline \multirow[t]{3}{*}{ PUF } & Kitchen & 0.003 & $\mathrm{NC}^{\mathrm{b}}$ & 0.79 & $\mathrm{NC}$ & 0.77 & 0.32 & 0.22 & 0.14 \\
\hline & Den & & $\mathrm{NC}$ & 0.25 & $\mathrm{NC}$ & 0.14 & 0.09 & 0.06 & 0.07 \\
\hline & Bedroom & & $\mathrm{NC}$ & 0.1 & $\mathrm{NC}$ & 0.07 & 0.06 & 0.04 & 0.03 \\
\hline \multirow[t]{3}{*}{ OVS } & Kitchen & 0.02 & $\mathrm{NC}$ & 1.00 & $\mathrm{NC}$ & 0.62 & 0.34 & 0.34 & 0.18 \\
\hline & Den & & $\mathrm{NC}$ & 0.33 & $\mathrm{NC}$ & 0.15 & $0.09(0.08)^{\mathrm{c}}$ & 0.06 & $0.06(0.05)^{\mathrm{c}}$ \\
\hline & Bedroom & & $\mathrm{NC}$ & $0.09(0.14)^{\mathrm{c}}$ & $\mathrm{NC}$ & 0.06 & 0.05 & 0.04 & 0.03 \\
\hline \multirow{3}{*}{$\begin{array}{l}\text { Total release } \\
\text { Aerosol }\end{array}$} & Living room & $\mathrm{ND}^{\mathrm{d}}$ & 15 & 9.2 & 4.1 & 2.3 & 0.86 & 0.45 & $\mathrm{NC}$ \\
\hline & Den & ND & 17 & 8.3 & 4.0 & 2.1 & 1.1 & 0.41 & $\mathrm{NC}$ \\
\hline & Bedroom & $\mathrm{NC}$ & 1.4 & 4.7 & $\mathrm{NC}$ & $\mathrm{NC}$ & 0.37 & 0.32 & $\mathrm{NC}$ \\
\hline
\end{tabular}

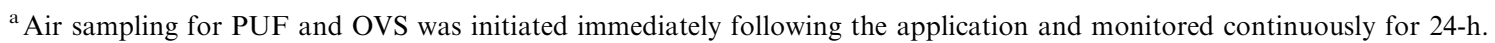

${ }^{\mathrm{b}} \mathrm{NC}$ indicates the sample was not collected.

${ }^{\mathrm{c}}$ The value in brackets represents a field duplicate sample.

${ }^{\mathrm{d}} \mathrm{ND}$ indicates the sample was not detected $<0.05 \mu \mathrm{g} / \mathrm{m}^{3}$.
} 
day 21. Chlorpyrifos, a semi-volatile compound with a vapor pressure of $1.7 \times 10^{-5} \mathrm{~mm} \mathrm{Hg}$ at $25^{\circ} \mathrm{C}$ (Tomlin, 1994), dispersed into the air and distributed from the source to other locations within the house over the 21day study period. The concentrations measured in the master bedroom decreased at a slower rate than the kitchen and den. The observed trend of the highest measured airborne concentrations occurring immediately following to several days post-application, followed by a steady decline to levels above background is consistent with studies where treatments were performed using different formulations of chlorpyrifos and application techniques (Byrne et al., 1998; Fenske et al., 1990; Gurunathan et al., 1998; Leidy et al., 1996; Lu and Fenske; 1998; Wright and Leidy, 1978).

\subsection{Deposition coupons}

Field and laboratory blanks showed no chlorpyrifos and represent pre samples. Chlorpyrifos measured from

\section{Table 2}

Chlorpyrifos concentrations measured from deposition coupons in the den and kitchen immediately following a crack and crevice application

\begin{tabular}{|c|c|c|c|c|c|}
\hline \multirow[t]{2}{*}{ Room } & \multirow[t]{2}{*}{$\begin{array}{l}\text { Position in } \\
\text { room by row }\end{array}$} & \multicolumn{4}{|c|}{$\begin{array}{l}\text { Concentration }\left(\mu \mathrm{g} / 100 \mathrm{~cm}^{2}\right) / \text { location } \\
\text { in room }\end{array}$} \\
\hline & & 1 & 2 & 3 & 4 \\
\hline \multirow[t]{3}{*}{ Den } & Left & 0.07 & 0.09 & 0.08 & 0.08 \\
\hline & Center & 0.09 & 0.08 & 0.07 & 0.07 \\
\hline & Right & 0.24 & 1.44 & 0.06 & 0.07 \\
\hline \multirow[t]{3}{*}{ Kitchen } & Left & 0.94 & 17.86 & 1.77 & 22.91 \\
\hline & Center & 1.19 & 0.41 & 0.66 & 0.66 \\
\hline & Right & 0.15 & 5.88 & 0.59 & 5.19 \\
\hline
\end{tabular}

the deposition coupons in the kitchen immediately following the application were variable (Table 2). The concentrations measured were highest at the floor/ cabinetry junction and lowest along the center row. The measurements collected from deposition coupons located in the den were uniform except for two deposition coupons with higher levels located along the wall that adjoins the kitchen below the "pass through". The application resulted in concentrations measured in both the treated kitchen and the untreated den. The pin-stream application delivered under pressure to the cracks and crevices produced localized splashing that resulted in a higher deposition of chlorpyrifos at the floor/cabinetry junction. The values shown in Fig. 2 represent the average mass of chlorpyrifos recovered from the combined deposition coupons from each room divided by the number of days the deposition coupons were exposed to give the average net daily deposition rate per sampling period. These values show a positive contribution of chlorpyrifos from the kitchen (source) onto the deposition coupons in both the den and bedroom. As shown in Fig. 2, surface deposition rates decreased to similar levels throughout the house by 21 days post-application.

\subsection{Carpet sections}

Background levels of chlorpyrifos were measured from the existing carpet collected prior to the application (Table 3). A non-homogenous distribution of chlorpyrifos is shown for samples collected at each day throughout the study with the highest values measured from the center of the den. Samples collected from the right and left rows suggest an increase in concentration over time. Background levels were detected in the bedroom, but increasing concentrations suggest a possible contribution from the application. However,

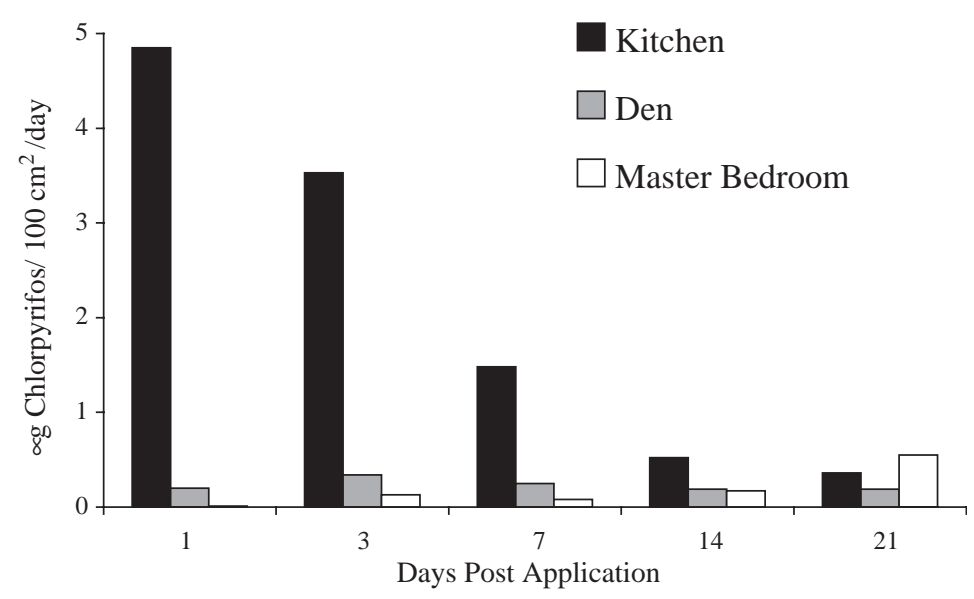

Fig. 2. The average net deposition rate of chlorpyrifos determined from deposition coupons in the kitchen, den and bedrooms at intervals following a crack and crevice application. 
Table 3

Chlorpyrifos measured from carpet sections from three locations in the den and the bedroom following a crack and crevice application in the IAQ Test House

\begin{tabular}{ccccc}
\hline Day & \multicolumn{2}{l}{ Location/concentration $\left(\mu \mathrm{g} / 100 \mathrm{~cm}^{2}\right)$} & \\
\cline { 2 - 4 } & Den & & Bedroom \\
\cline { 2 - 4 } & Left & Center & 1.72 & 0.91 \\
\hline Pre & 1.18 & 9.83 & $2.71(3.03)^{\mathrm{c}}$ & 0.89 \\
$1^{\mathrm{b}}$ & 1.56 & 3.51 & 2.38 & 1.10 \\
3 & 1.77 & 7.20 & 3.22 & 1.14 \\
7 & 1.78 & 11.70 & 3.40 & 1.25 \\
14 & 2.11 & 7.72 & 4.31 & 1.25 \\
\hline 1 & 2.51 & 4.94 & & \\
\hline
\end{tabular}

\footnotetext{
${ }^{\mathrm{a}}$ The value represents an aggregation of five samples.

${ }^{\mathrm{b}}$ The samples were collected immediately following the application.

${ }^{\mathrm{c}}$ The value in brackets represents a duplicate field sample.
}

the high background levels measured from carpeting confound all values. A previous application of chlorpyrifos was performed at the research house in 1993 using a TRA where approximately $1.7 \mathrm{~g}$ was applied in the den and living room (Mason et al., 2000). The levels measured from carpet may represent residue sorbed to the carpet or bound to particles from that treatment. The higher average concentrations measured from the carpet collected from the center row of the den are in the general proximity where a TRA was activated in the previous study. Arguably, the background levels may have been associated with intrusion from sources not related to this or the previous application. Despite the fact that background levels confound the interpretation of the data in terms of the contribution of this application it is likely that at least some of the chlorpyrifos measured here was associated with the previous application and suggests the longevity of chlorpyrifos indoors and carpeting as a sink for these residues.

\subsection{Comparison of two application methods}

In the study conducted by Mason et al. the distribution of chlorpyrifos following the activation of two TRA's was examined. Specifically the aerosols were activated in the den and living room in the EPA IAQ research house. Air and surface deposition evaluations (using a similar type deposition coupon) were performed in the den, living room and master bedroom following the application. Airborne concentrations were collected approximately $3 \mathrm{~h}$ following the application and at 1,2, 3, 7 and 14 days post application. Deposition coupons were placed before the release and collected approximately $3 \mathrm{~h}$ following the application. An important difference that further distinguishes the two studies is that interior doors remained closed throughout the TRA experiment, effectively increasing the air exchange rate from that measured in the crack and crevice study by approximately $80 \%$. Following the activation of the aerosol cans, the house was closed for $2 \mathrm{~h}$ followed by a $1 \mathrm{~h}$ venting period where windows were opened in the treated rooms. The air samples collected were of 1-h duration at approximate flow rates of $15 \mathrm{l} / \mathrm{min}$. Other studies have demonstrated differences between these and other application approaches and typically have shown that crack and crevice type applications produce lower airborne concentrations than TRA or broadcast type applications. However, these studies have not examined air and surface residues more than hours or days beyond the application (Ross et al., 1990, 1991; Fenske et al., 1990; Lu and Fenske, 1998, 1999). Airborne residues following broadcast applications (an application more similar to the TRA than the crack and crevice application) have shown that peak chlorpyrifos concentrations occur between 4 and $8 \mathrm{~h}$ post application (Fenske et al., 1990; Lu and Fenske, 1998). Therefore, the values measured in Mason et al. at $3 \mathrm{~h}$ may not represent the peak airborne concentrations. For purposes of comparison with the crack and crevice application, which utilized $24 \mathrm{~h}$ sampling intervals, the measurements collected at 3 and $24 \mathrm{~h}$ post application were averaged to give $12.1,12.7$ and $3.1 \mu \mathrm{g} / \mathrm{m}^{3}$ for the den, living room and master bedroom, respectively. Results related to airborne concentrations from Mason's study are presented in Table 2. The crack and crevice and TRA applications resulted in a total theoretical mass of 1.3 and $1.7 \mathrm{~g}$ of chlorpyrifos, respectively. Airborne concentrations measured immediately following the TRA application were higher at day 1 and had markedly declined by day 14 . Values were similar in the two rooms where TRA applications were activated and were approximately 4 times higher than the master bedroom. Both the crack and crevice and the TRA applications resulted in the distribution of residues to the most distant point in the house (master bedroom). 
Comparatively, 24-h average airborne concentrations in the den $\left(12.1 \mu \mathrm{g} / \mathrm{m}^{3}\right)$ immediately following the TRA application were 16 times higher than those in the kitchen $\left(0.79 \mu \mathrm{g} / \mathrm{m}^{3}\right)$ following the crack and crevice application. Similarly, the TRA applications resulted in post application 24-h average air concentrations in the master bedroom that were about 30 times higher. Similar comparisons at 14 days show that concentrations resulting from the TRA application remained 8 and 2 times higher than those resulting from the crack and crevice application. The TRA resulted in higher airborne concentrations. The $1-\mathrm{h}$ venting period associated with the TRA application was insufficient to clear the chlorpyrifos from the indoor air. The concentrations measured from deposition coupons following the TRA application ranged from 280 to $703 \mu \mathrm{g} / 100 \mathrm{~cm}^{2}$ in the living room, $290-720 \mu \mathrm{g} / 100 \mathrm{~cm}^{2}$ in the den and $23-$ $44 \mu \mathrm{g} / 100 \mathrm{~cm}^{2}$ in the master bedroom. The concentrations on deposition coupons associated with the TRA were higher than those associated with the crack and crevice application, but both applications resulted in distributions onto coupons in all the rooms throughout the study. Significant and potentially important differences between the two studies (such as open and closed doors, venting periods and fewer sampling intervals) confound absolute comparisons and make it difficult to fully explain the reasons for the prolonged higher levels for the TRA application, particularly in the master bedroom. The crack and crevice application, by placing deposits in discrete and protected locations, reduced the distribution to other locations in the house. Conversely, the evacuation of the contents of the TRA into air likely was an important factor contributing to the measurement of overall higher concentrations and since the TRA application directs spray over a large surface area (such as furnishings, floors, carpets, walls, etc.), the increased total surface area treated relative to that of the crack and crevice treatment likely further contributed to these observed differences. Additional investigation is required to clarify the influence of the doors remaining closed throughout the TRA experiment, emissions from residues on interior surfaces and the active air conditioning system.

\subsection{Non-dietary dose estimates}

The stochastic human exposure and dose simulation (SHEDS) model for pesticides (Zartarian et al., $2002 \mathrm{a}, \mathrm{b})$ was used to estimate the exposures and absorbed doses associated with the two application scenarios for children 3-6 years of age. The populationbased SHEDS model simulates individuals from userspecified population cohorts by selecting daily sequential time-location-activity diaries from surveys contained in EPA's Consolidated Human Activity Database (CHAD; McCurdy et al., 2000) relevant to the specified demo- graphic (age, gender, etc.) factors. Each simulated individual is randomly assigned an appropriate activity diary according to demographic characteristics and the values for each model input parameter are randomly sampled from distributions and inserted into pathwayalgorithms. An individual's time series of exposure and dose by pathway is estimated and the metric of interest (e.g., time-averaged aggregate dose) is computed for the individual. The process is repeated thousands of times using Monte Carlo simulation to produce a population distribution of exposure or dose.

For this modeling exercise, the airborne concentrations from the TRA application are averages of the 3- and 24-h integrated samples. Since no surface measurements were collected at day 14 for the TRA application, a 10\% decay rate was assumed to estimate inputs for the dermal and indirect ingestion exposures. The estimated daily inhalation time series dose profile resultant from exposure to airborne concentrations was estimated as a product of the airborne concentration $\left(\mu \mathrm{g} / \mathrm{m}^{3}\right)$, a basal breathing rate $\left(\mathrm{m}^{3}\right.$ air/day), an activity-specific ventilation rate ratio, the duration of the macroactivity event (day/event). The dermal estimated exposure time series dose profile was calculated as a product of the deposition coupon concentration $\left(\mu \mathrm{g} / \mathrm{cm}^{2}\right)$, the dermal transfer coefficients for a given macroactivity $\left(\mathrm{cm}^{2} / \mathrm{h}\right)$ for the hand and body, and the duration of the macroactivity (h/event). In addition to mass loading, removal mechanisms also considered by the model such as hand washing, bathing, and hand-to-mouth transfers. An estimated non-dietary ingestion dose profile included exposure from hand- and object-to-mouth activities. The time-integrated dermal exposure for the child's hands $(\mu \mathrm{g})$ was halved to represent the mass loading to one hand since it is rare that both hands enter the mouth at the same time. The mass was then adjusted for the fraction of residue on the hand that contacts the mouth per mouthing event $(1 /$ mouthing event) and the saliva removal efficiency (fraction of contact that is transferred). This available residue was multiplied by the frequency (mouthing events/h) and the duration (h/event). For the estimated object-to-mouth dose the deposition coupon concentration $\left(\mu \mathrm{g} / \mathrm{cm}^{2}\right)$ was first adjusted for residue transfer to the object and then the object surface area that contact the mouth $\left(\mathrm{cm}^{2} /\right.$ mouthing event) and the saliva removal efficiency was calculated. The estimated dose was a product of this available residue, the frequency (mouthing event/h) and the duration (h/event). Finally, the daily aggregate dose $(\mu \mathrm{g} / \mathrm{kg} / \mathrm{day})$ was calculated as the arithmetic sum of the resultant absorbed dose obtained from each route of exposure utilizing route-specific absorption factors and the simulated individual's body weight. Relevant parameters utilized in the model and their estimates are given in Table 4.

The findings presented in Table 5 show the estimated absorbed dose across three routes of exposure for 3-6 
Table 4

SHEDS model input parameters

\begin{tabular}{|c|c|c|c|c|c|c|}
\hline \multirow[t]{2}{*}{ Input parameters } & \multirow[t]{2}{*}{ Distribution type } & \multicolumn{3}{|c|}{ Parameter estimate $^{\mathrm{a}}$} & \multirow[t]{2}{*}{ Units } & \multirow[t]{2}{*}{ Reference } \\
\hline & & $v_{1}$ & $v_{2}$ & $v_{3}$ & & \\
\hline $\begin{array}{l}\text { Fraction of time in treated } \\
\text { room }\end{array}$ & Point & 0.43 & & & & Hore (2003) \\
\hline $\begin{array}{l}\text { Child's dermal hand transfer } \\
\text { coefficient indoors }\end{array}$ & Lognormal & 2029 & 5 & & $\mathrm{~cm}^{2} / \mathrm{h}$ & Hore (2003) \\
\hline $\begin{array}{l}\text { Child's dermal body transfer } \\
\text { coefficient }\end{array}$ & Lognormal & 5900 & 3.8 & & $\mathrm{~cm}^{2} / \mathrm{h}$ & Hore (2003) \\
\hline Object-surface residue ratio & Point & 0.5 & & & & Best estimate \\
\hline $\begin{array}{l}\text { Textured surface-to-skin } \\
\text { residue transfer efficiency }\end{array}$ & Lognormal & 0.0032 & 4.12 & & & Zartarian et al. (2000) \\
\hline $\begin{array}{l}\text { Smooth surface-to-skin } \\
\text { residue transfer efficiency }\end{array}$ & Uniform & 0.7 & 10 & & $\%$ & Zartarian et al. (2000) \\
\hline Hand washing events per day & Triangle & 1 & 4 & 10 & $\%$ & EPA (2002) \\
\hline $\begin{array}{l}\text { Hand washing removal } \\
\text { efficiency }\end{array}$ & Uniform & 0.3 & 0.9 & & & Best estimate \\
\hline Bathing removal efficiency & Uniform & 0.7 & 1 & & & Best estimate \\
\hline $\begin{array}{l}\text { Maximum dermal loading } \\
\text { hands }\end{array}$ & Uniform & 0.1 & 2 & & $\mu \mathrm{g} / \mathrm{cm}^{2}$ & $\begin{array}{l}\text { Ross et al. (1990), Cohen } \\
\text { Hubal (2002) }\end{array}$ \\
\hline $\begin{array}{l}\text { Maximum dermal loading } \\
\text { body }\end{array}$ & Uniform & 0.1 & 0.7 & & $\mu \mathrm{g} / \mathrm{cm}^{2}$ & Ross et al. (1990) \\
\hline $\begin{array}{l}\text { Fraction of hands with residue } \\
\text { going to mouth }\end{array}$ & Triangle & 0.025 & 0.05 & 0.3 & & Leckie et al. (2000) \\
\hline $\begin{array}{l}\text { Frequency of hand-to-mouth } \\
\text { activity }\end{array}$ & Lognormal & 9 & 2.4 & & events/h & $\begin{array}{l}\text { Reed (1998), Tulve et al. } \\
\text { (2002) }\end{array}$ \\
\hline Saliva removal efficiency & Uniform & 0.1 & 0.5 & & & Zartarian et al. (2000) \\
\hline $\begin{array}{l}\text { Surface area of objects } \\
\text { inserted in mouth }\end{array}$ & Lognormal & 10 & 1.3 & & $\mathrm{~cm}^{2} /$ event & Leckie et al. (2000) \\
\hline $\begin{array}{l}\text { Frequency of object to mouth } \\
\text { activity }\end{array}$ & Triangle & 0 & 1 & 40 & events/h & $\begin{array}{l}\text { Reed (1998), Tulve et al. } \\
\text { (2002) }\end{array}$ \\
\hline $\begin{array}{l}\text { Dermal absorption rate for } \\
\text { liquids }\end{array}$ & Lognormal & $2.4 \mathrm{E}-07$ & 1.3 & & $/ \mathrm{s}$ & $\begin{array}{l}\text { Nolan et al. (1984), Griffin } \\
\text { et al. (1999) }\end{array}$ \\
\hline GI absorption rate & Lognormal & 0.00025 & 3.5 & & $/ \mathrm{s}$ & Nolan et al. (1984) \\
\hline Inhalation absorption factor & Triangle & 0.5 & 0.9 & 1 & & Best estimate \\
\hline Bioavailable fraction & Normal & 0.74 & 0.13 & & & $\begin{array}{l}\text { Nolan et al. (1984), Griffin } \\
\text { et al. (1999) }\end{array}$ \\
\hline
\end{tabular}

\footnotetext{
${ }^{\mathrm{a}} \mathrm{A}$ distribution $\left(v_{1}, v_{2}, v_{3}\right)$ : triangle (minimum, mode, maximum); uniform (minimum, maximum); normal (mean, standard
} deviation); lognormal (geometric mean, geometric standard deviation).

year-old children at days 1 and 14 following the crack and crevice and TRA applications. The crack and crevice application resulted in doses that were highest immediately following the application and declined by half by 14 days for both inhalation and indirect ingestion, but declined less for dermal exposures. These findings suggest that indirect ingestion is the more important exposure pathway at both days 1 and 14 representing over $90 \%$ of the total exposure dose for this type application. The TRA mean inhalation dose decreased from 1 to 14 days post application, while the indirect and dermal doses declined only slightly. Indirect ingestion remained the predominant route of exposure for the TRA application representing $81 \%$ and $95 \%$ of the total dose at 1 and 14 days, respectively. The TRA resulted in higher doses across all routes of exposure, with aggregate doses between 3 and 5 times higher than the crack and crevice application.

Although the total theoretical mass of chlorpyrifos administered during the crack and crevice and TRA applications were nearly equivalent, the TRA application resulted in doses across all pathways that were markedly higher than those of the crack and crevice application. It is notable that the intention of crack and crevice applications is to place active ingredient into void areas where pests harbor and thereby reduce potential human exposures. Based on these findings, the crack and crevice application would reduce the level of exposure immediately following the application relative to the TRA. The National Academy of Science 
Table 5

Dose estimates across three exposure pathways for children between 3 and 6 years of age using the SHEDS model

\begin{tabular}{|c|c|c|c|c|c|c|c|}
\hline \multirow[t]{2}{*}{ Treatment } & \multirow[t]{2}{*}{ Day } & \multirow[t]{2}{*}{$N$} & \multirow[t]{2}{*}{ Exposure pathway $(\mu \mathrm{g} / \mathrm{kg} /$ day $)$} & \multirow[t]{2}{*}{ Mean $( \pm$ SD $)$} & \multicolumn{2}{|c|}{ Percentiles } & \multirow[t]{2}{*}{ Median } \\
\hline & & & & & 5 & 95 & \\
\hline \multirow[t]{8}{*}{$\mathrm{C} \& \mathrm{C}$} & 1 & 1999 & \multirow[t]{2}{*}{ Inhalation } & $0.09(0.06)$ & 0.03 & 0.19 & 0.08 \\
\hline & 14 & 1999 & & $0.03(0.02)$ & 0.007 & 0.06 & 0.03 \\
\hline & 1 & 2000 & \multirow[t]{2}{*}{ Indirect Ingestion } & $3.1(3.6)$ & 0.2 & 9.6 & 1.9 \\
\hline & 14 & 2000 & & $1.5(1.6)$ & 0.1 & 4.5 & 1 \\
\hline & 1 & 2000 & \multirow[t]{2}{*}{ Dermal (hand) } & $0.08(0.07)$ & 0.0013 & 0.23 & 0.06 \\
\hline & 14 & 2000 & & $0.06(0.05)$ & 0.007 & 0.15 & 0.04 \\
\hline & 1 & 2000 & \multirow[t]{2}{*}{ Aggregate } & $3.3(3.6)$ & 0.3 & 10 & 2.1 \\
\hline & 14 & 2000 & & $1.6(1.6)$ & 0.1 & 4.7 & 1 \\
\hline \multirow[t]{8}{*}{ TRA } & 1 & 2000 & \multirow[t]{2}{*}{ Inhalation } & $1.7(0.7)$ & 0.8 & 3.2 & 1.6 \\
\hline & 14 & 2000 & & $0.11(0.05)$ & 0.04 & 0.2 & 0.1 \\
\hline & 1 & 2000 & \multirow[t]{2}{*}{ Indirect Ingestion } & $8.8(7.6)$ & 1.3 & 24 & 6.4 \\
\hline & 14 & 2000 & & $8.1(7.3)$ & 0.8 & 22 & 6.2 \\
\hline & 1 & 2000 & \multirow[t]{2}{*}{ Dermal (hand) } & $0.3(0.2)$ & 0.06 & 0.7 & 0.3 \\
\hline & 14 & 2000 & & $0.3(0.2)$ & 0.05 & 0.7 & 0.3 \\
\hline & 1 & 2000 & \multirow[t]{2}{*}{ Aggregate } & $11(8.0)$ & 2.6 & 27 & 8.6 \\
\hline & 14 & 2000 & & $8.5(7.5)$ & 1 & 23 & 6.3 \\
\hline
\end{tabular}

(NAS) established an interim guideline of $10 \mu \mathrm{g} / \mathrm{m}^{3}$ for chlorpyrifos for indoor air following a termiticide application (National Academy of Sciences, 1988). Here, the crack and crevice application resulted in airborne concentrations at day 1 that were $8 \%$ of the NAS guidelines, while the TRA day 1 average airborne concentrations exceeded those values. The Environmental Protection Agency human oral reference dose for chlorpyrifos (US Environmental Protection Agency, 2002 ) is $3 \mu \mathrm{g} / \mathrm{kg} /$ day (reflective of a 10-fold safety factor to the human no observed effect level). The aggregate dose values for the TRA application slightly exceeded the oral reference dose immediately following the application, but did not for the crack and crevice application. By day 14 the potential dose received from both the TRA and the crack and crevice application had declined to levels below the oral reference dose. This indicates that both the crack and crevice and TRA applications present increased potential risk immediately following the application but by day 14 the risk may be decreased. Additional studies are required to further evaluate potential exposures following the use of these application approaches in homes, particularly beyond 14 days post application for TRA and consider scenarios where multiple applications might be performed.

\section{Conclusions}

Crack and crevice type applications in current use by pest control operators locate insecticides in cockroach harborage sites and minimize human exposure to the residues. Here, chlorpryrifos administered to the cracks and crevices in the kitchen resulted in airborne residues and deposition onto non-target surfaces. The high levels measured from the kitchen floor and at two locations in the den were likely due to the application factors such as over spray and splashing. Residues measured from the kitchen floor immediately following the application were non-uniform in distribution and may be important when developing sampling plans for future studies examining crack and crevice applications. Chlorpyrifos rapidly distributed within the house and diffusive processes were likely important in the immediate dispersion from the point of application. However, the active air conditioning system was also likely a significant factor. Additional studies are required to better understand the interaction of a semi-volatile compound, such as chlorpyrifos, with indoor surfaces and the air exchange between rooms. Based on the pesticides distribution throughout the house, many exposed surfaces might be contaminated and serve as potential sources for human exposure, particularly for children playing on the floor at or near the point of application. The exposure assessment conducted here suggests TRA type applications pose a higher potential risk than crack and crevice applications. The high concentrations detected in the carpet sections suggest that residues persist for a long time in some carpets and may need to be considered further as emphasis is placed on children's chronic exposure to indoor pesticides. Hence indoor monitoring programs and the resulting exposure estimates may need to evaluate the fate, behavior and distribution of pesticides up to and beyond 21 days post-application. 
Since the inception of this experiment, registrations allowing for the indoor application of chlorpyrifos have been withdrawn. However, these finding are representative of crack and crevice applications of semi-volatile compounds like chlorpyrifos and its distribution from the point of application. Pyrethroid insecticides and baits are currently popular in residential pest control in both the consumer and professional market. Transport mechanisms, and spatial distributions are expected to be different and may not be represented adequately by these findings. Research conducted by Berger-Preib et al. (1997) suggests the translocation of pyrethroids indoors may be more influenced by the movement of particle bound residues than by vapors in air. This would suggest that physical processes such as human activity might play a more important role in the exposure scenario. Further evaluation is required to understand the impact on exposures that may result as the chemical properties of the insecticide classes shift from semi-volatile organophosphorus compounds, such as chlorpyrifos, to pyrethroid insecticides, many of which are essentially non-volatile. In terms of risk assessment, such a shift suggests that the importance of the inhalation exposure pathway might decrease while the role of direct and particularly indirect exposures might increase.

\section{Acknowledgements}

The United States Environmental Protection Agency through its Office of Research and Development funded and managed the research described here. It has been subjected to Agency's administrative review and approved for publication as an EPA document.

\section{References}

ASHRAE, 1985. ASHRAE Handbook of Fundamentals. American Society of Heating, Refrigeration and Air Conditioning Engineers, Inc., Atlanta, GA, p. 228.

Berger-Preib, E., Preib, A., Sielaff, K., Raabe, M., Ilgen, B., Levsen, K., 1997. The behavior of pyrethroids indoors: a model study. Indoor Air 7, 248-261.

Byrne, S.L., Saunders, D.G., Sherdut, B.A., 1998. Potential chlorpyrifos exposure to residents following standard crack and crevice treatment. Environmental Health Perspectives 106 (11), 725-731.

Cohen Hubal, E., 2002. EPA National Exposure Research Laboratory, personal communication.

Fenske, R.A., Black, K.G., Elkner, K.P., Lee, C.L., Methner, M.M., Soto, R., 1990. Potential exposure and health risks of infants following indoor residential pesticide applications. American Journal of Public Health 80 (6), 689-693.

Griffin, P., Mason, H., Heywood, K., Cocker, J., 1999. Oral and dermal absorption of chlorpyrifos: a human volunteer study. Occupational and Environmental Medicine 56, $10-13$.

Gurunathan, S., Robson, M., Freeman, N., Buckley, B., Roy, A., Meyer, R., Bukowski, J., Lioy, P.J., 1998. Accumulation of chlorpyrifos on residential surfaces and toys accessible to children. Environmental Health Perspectives. 106 (1), 9-16.

Hore, P., 2003. Pesticide accumulation patterns for child accessible surfaces and objects and urinary metabolite excretion by children for two weeks after a professional crack and crevice application. Rutgers Dissertation, New Brunswick, NJ.

Leckie, J.O., Naylor, K.A., Canales, R.A., Ferguson, A.C., Cabrera, N.L., Hurtado, A.L., Lee, K., Lin, Y., Ramirez, A., Vieria, J.D., 2000. Quantifying children's microlevel activity data from existing videotapes. Contract Report Submitted to US EPA, ORD, NERL, Reference No. U2F112OT-RT.

Leidy, R.B., Wright, C.B., Dupree Jr., H.E., 1993. Exposure levels to indoor pesticides. In: Racke, K.D., Leslie, A.R. (Eds.), Pesticides in Urban Environments, ACS Symposium Series 522. American Chemical Society, Washington, DC, pp. 282-295.

Leidy, R.B., Wright, C.G., Dupree Jr., H.E., 1996. Distribution of chlorpyrifos in air and on surfaces in rooms after a crack and crevice application. Environmental Monitoring and Assessment 42, 253-263.

Lewis, R.G., Fortune, C.F., Blanchard, F.T., Camann, D.E., 2001. Movement and deposition of two organophosphorus pesticides within a residence after interior and exterior applications. Journal of Air and Waste Management Association 51, 339-351.

Lu, C., Fenske, R.A., 1998. Air and surface chlorpyrifos residues following residential broadcast and aerosol pesticide applications. Environmental Science Technology 32 (10), 1386-1390.

Lu, C., Fenske, R.A., 1999. Dermal transfer of chlorpyrifos residues from residential surfaces; comparisons of hand press. Hand drag wipe, and polyurethane foam roller measurements after broadcast and aerosol applications. Environmental Health Perspectives 107 (6), 463-467.

Mason, M.A., Sheldon, L.S., Stout II, D.M., 2000. The distribution of chlorpyrifos in air, carpeting, and dust and its reemission from carpeting following the use of total release aerosols in and an indoor air quality test house. Proceedings of the Symposium on Engineering Solutions to Indoor Air Quality Problems, Raleigh, NC, 17-19 July, pp. 92-102.

McCurdy, T., Glen, G., Smith, L., Lakkadi, Y., 2000. The National Exposure Research Laboratory's consolidated human activity database. Journal of Exposure Analysis and Environmental Epidemiology 10 (6), 566-578.

National Academy of Sciences, 1988. National Academy of Sciences: An Assessment of Health Risks of Seven Pesticides Used for Termite Control. National Research Council Committee on Toxicology. National Academy Press, Washington, DC.

Nishioka, M.G., Burkholder, H.M., Brinkman, M.C., Gordon, S.M., Lewis, R.G., 1997. Simulation of track-in of lawnapplied pesticides from turf to home: comparisons of dislodgeable turf residues with carpet dust and carpet 
surface residues. Report No. EPA/600/R-97/108, United States Environmental Protection Agency, National Exposure Research Laboratory, Research Triangle Park, NC.

Nolan, R.J., Rick, D.L., Freshour, N.L., Saunders, J.H., 1984. Chlorpyrifos: pharmacokinetics in human volunteers. Toxicology and Applied Pharmacology 73, 8-15.

Reed, K.J., 1998. Quantification of children's hand and mouthing activities through a videotaping methodology. Ph.D. Dissertation, Graduate School-New Brunswick, Rutgers University.

Ross, J., Thongsinthusak, T., Fong, H.R., Margetich, S., Kreiger, R., 1990. Measuring potential dermal transfer of surface pesticide residue generated from indoor fogger use; an interim report. Chemosphere 20 (3-4), 349-360.

Ross, J., Thongsinthusak, T., Fong, H.R., Margetich, S., Kreiger, R., 1991. Measuring potential dermal transfer of surface pesticide residue generated from indoor fogger use; using the CDFA roller method interim report II. Chemosphere 22 (9-10), 975-984.

Stout II, D.M., Leidy, R.B., 2000. A preliminary examination of the translocation of microencapsulated cyfluthrin following applications to the perimeter of residential dwellings. Journal of Environmental Science and Health Part B B35 (4), 477-489.

Tomlin, C. (Ed.), 1994. The Pesticide Manual, 10th Edition. The Royal Society of Chemistry, Cambridge, UK.

Tulve, N.S., Suggs, J., McCurdy, T., Cohen Hubal, E., Moya, J., 2002. Frequency of mouthing behavior in young children. Journal of Exposure Analysis and Environmental Epidemiology 12, 259-264.

US Environmental Protection Agency, 2002. Child-specific Exposure Factors Handbook (interim report). USEPA EPA-600-P-00-002B, 01 September 2002. US Environmental Protection Agency, Office of Research and Development, National Center for Environmental Assessment, Washington Office, Washington, DC, 448pp.

Wright, C.G., Leidy, R.B., 1978. Chlorpyrifos residues in air after application to crevices in rooms. The Bulletin of Environmental Contamination and Toxicology 20, 340-344.

Zartarian, V.G., Ozkaynak, H., Burke, J.M., Zufall, M.J., Rigas, M.L., Furtaw Jr., E.J., 2000. A modeling framework for estimating children's residential exposure and dose to chlorpyrifos via dermal residue contact and non-dietary ingestion. Environmental Health Perspectives 108 (6), $505-514$.

Zartarian, V.G., Xue, J., Ozkaynak, H., 2002a. Quantifying aggregate chlorpyrifos exposure and dose to children using a physically based two-stage Monte Carlo probabilistic model. Society for Risk Analysis Conference, New Orleans, LA, 8-11 December.

Zartarian, V.G., Xue, J., Ozkaynak, H., Glen, G., Smith, L., Stallings, C., 2002b. Modeling Activities Addressing National Issues: Aggregate Exposure Model Comparison Workshop. Peer Review of NERL's Human Exposure University Partnerships Agreement Modeling Program, Arlington, VA, 8-10 July. 